[2] Mok MY, Li WL. Do Asian patients have worse lupus? Lupus 2010;19:13841390.

[3] Morisky DE, et al. Predictive Validity of a Medication Adherence Measure in an Outpatient Setting. J Clin Hypertens 2008:10:348-354.

[4] George J, et al. Developmennt and Validation of the Medication Regimen Complexity Index. Ann Pharmacoepidemiol 2004;38:1369-1376.

Disclosure of Interest: None declared

DOI: 10.1136/annrheumdis-2017-eular.1819

\section{AB1095 EARLY DIAGNOSIS AND TREATMENT OF CHRONIC DISEASES: NATIONAL REVIEW AND GUIDELINES - RA AS AN EXAMPLE}

L. Euller Ziegler on behalf of the High Council for Public Health (HCSP). Rheumatology Department, Academic Hospital and University of Nice, Nice, France

Background: Managing the increasing burden of chronic diseases is a major public health problem. Are early diagnosis and management a key point for their optimal care and outcome?

Objectives: Assessing early diagnosis and management of chronic diseases was the aim of a study carried out by the High Council for Public Health (HCSP), independent national body gathering experts nominated by the Minister of Health, to provide health authorities with expertise on development of national public health goals, assess their achievement and contribute to their monitoring

Methods: A multidisciplinary working party run within the HCSP a review of scientific data supporting early intervention benefits, as well as frequency, impact and mechanisms of delayed management on individuals and society, in order to produce national guidelines. A huge amount of data were analyzed:argued contributions from national Professional organizations and Patient associations, literature analysis, audition of national agencies representatives.

Results: Early stages of chronic diseases are less studied than later ones.Nevertheless, there is a strong evidence that delayed diagnosis and management are frequent and often adversely affect patients and society. The frequency, length and burden of delayed care were analyzed, varying with each disease, availability of efficient treatments and guidelines, socio-economic context. Optimal time for adequate management from symptom onset was reviewed, as well as medico-economic studies

Rheumatologic disorders appeared as models, notably Rheumatoid Arthritis (wellestablished window of opportunity, international guidelines for early diagnosis and management, including T2T and patient active implication). Evidence for early treatment benefit was also found for spondyloarthritis, osteoporosis, obstructive sleep apnea syndrome, chronic obstructive pulmonary disease, renal insufficiency, autism spectrum disorders, bipolar disorders, ... Ethical considerations may arise; in Alzheimer's disease, a diagnosis source of marked anxiety, there is no effective pharmacological treatment- but non pharmacological treatments are quite helpful for patients and family and therefore recommended by health authorities.

Obviously, the benefit of early intervention must be strongly assessed. When this benefit is proven, too many patients are facing delays, often long, with adverse consequences and increased burden for society. The mechanisms of such delayed management are multiple and often intricate; we analyzed the barriers to optimal care linked with professionals, patients, family, health system and society, in order to identify the ways to optimize the outcomes and therefore improve the global health status of the population.

Finally the HCSP established a set of guidelines, in 3 axis

- disseminate widely the available knowledge among professionals, patients, the general public, taking into account the social poor perception of chronic diseases

- implement effectively change in practice toward early treatment, when appropriate:timely coordination between professionals and patient, fair diagnosis announcement, early patient implication, fight against social health inequalities

- develop research on early stages of chronic diseases, diagnosis, management and outcomes.

Conclusions: From a national public health perspective, early diagnosis and management, in the chronic diseases where their benefit is proven, should be better known and effectively implemented.

Disclosure of Interest: None declared

DOI: 10.1136/annrheumdis-2017-eular.4038

\section{AB1096 TIMED UP AND GO TEST (TUG) FOR SARCOPENIA SCREENING}

L.I. Filippin ${ }^{1}$, V.O.N. Teixeira ${ }^{2}$, N.C. Oliviera ${ }^{3}$, D.D. Berwanger ${ }^{4}$, F. Miraglia ${ }^{1}$. ${ }^{1}$ Program Post-graduat Saúde e Desenvolvimento Humano, Centro Universitário la Salle, Canoas/RS, Canoas: ${ }^{2}$ Post-doctoral Fellow, Universidade Federal de Ciências da Saúde de Porto Alegre, Porto Alegre; ${ }^{3}$ Physiotherapy Graduate; ${ }^{4}$ Physical Education Graduate, Centro Universitário la Salle, Canoas/RS, Canoas, Brazil

Background: Sarcopenia is a multifactorial syndrome characterized by a decrease of muscle mass and force together with functional performance impairment. Sarcopenia has been described as an independent predictor factor of health adverse outcomes such as falls, decreased quality of life, enhanced risk of death and higher treatment costs. However, there are just a few screening tolls of low cost and easy applicability to detect sarcopenia. In this context, a standard mobility assessment such as the TUG test has recently been described as a predictor of sarcopenia.

Objectives: To evaluate the performance of timed up and go test (TUG) as a screening toll for sarcopenia in the elderly.

Methods: This is a cross-sectional home study with 211 elderly participants of the South Region of Brazil. Sarcopenia diagnosis criteria was based on the European Working Group on Sarcopenia in Older People (EWGSOP). Individuals that presented low muscle mass (women: $\leq 6.37 \mathrm{~kg} / \mathrm{m}^{2}$ and men: $\leq 8.90 \mathrm{~kg} / \mathrm{m}^{2}$ ) added to decreased handgrip strength (women: <20kgf and men: <30kgf) and $/$ or walking speed $(\leq 0.8 \mathrm{~m} / \mathrm{s})$ were considered sarcopenic. TUG test quantifies functional mobility through the task of getting up from a chair, walking $3 \mathrm{~m}$ and come back to sit on the chair.

Results: Based on EGWSOP criteria for sarcopenia, $17.1 \%(n=36)$ received the sarcopenia diagnosis. A ROC curve was constructed to evaluate the discriminatory power of TUG (AUC: 0.73 [IC $0.67-0.78 ; p=0.0001]$ ). TUG test presented high sensibility $(88.9 \%)$ and negative predictive values $(93.2 \%)$, with a cutoff point of 7.5 seconds (figure 1 ).

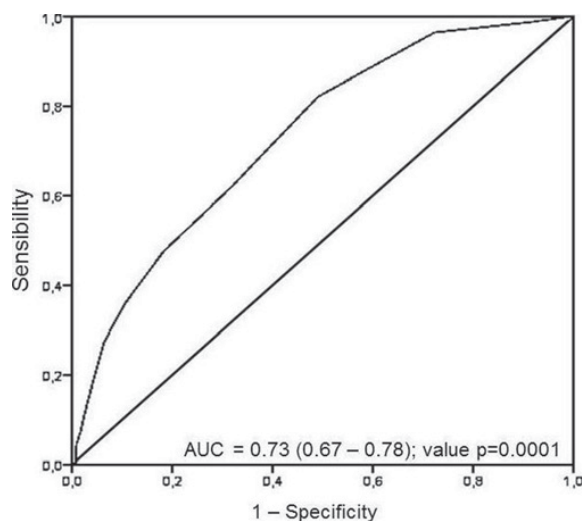

Conclusions: Detecting the beginning of sarcopenia could allow for early interventions and slow the syndrome process, preventing further hospitalizations and economic burden. In this context, TUG is an easy, fast and low-cost test with high sensibility for sarcopenia detection that could be used as screening toll for this syndrome.

References:

[1] Barbosa-Silv TG, Bielemann RM, Gonzalez MC, et al. Journal of Cachexia, Sarcopenia and Muscle. 2016; 7:136-143.

[2] Cruz-Jentoft AJ, Baeyens JP, Bauer JM, Boirie Y, Cederholm T, Landi F, et al. Age Ageing. 2010;39(4):412-23.

[3] da Silva Alexandre T, de Oliveira Duarte YA, Ferreira Santos JL, Wong R, Lebrão ML. J Nutr Health Aging. 2014;18(8):751-6.

[4] Ishii S, Tanaka T, Shibasaki K, Ouchi Y, Kikutani T, Higashiguchi T, et al. Geriatr Gerontol Int. 2014;14 Suppl 1:93-101.

[5] Malmstrom TK, Morley JE. J Am Med Dir Assoc. 2013;14(8):531-2.

[6] Martinez BP, Gomes IB, Oliveira CS, Ramos IR, Rocha MD, Forgiarini Júnior LA, et al. Clinics (Sao Paulo). 2015;70(5):369-72.

Acknowledgements: Conselho Nacional de Desenvolvimento Científico e Tecnológico (CNPq); Fundação de Amparo à Pesquisa do Estado do Rio Grande do Sul (FAPERGS).

Disclosure of Interest: None declared

DOI: 10.1136/annrheumdis-2017-eular.2385

\section{AB1097 PATIENTS' EXPERIENCES OF REMOTE MONITORING OF RHEUMATOID ARTHRITIS USING A SMARTPHONE APP}

L. Austin ${ }^{1}$, C. Sanders ${ }^{1}$, W. Dixon ${ }^{2} .{ }^{1}$ Centre for Primary Care, Faculty of Biology, Medicine and Health, Manchester Academic Health Science Centre; ${ }^{2}$ Arthritis UK Centre for Epidemiology, Centre for Musculoskeletal Research, Faculty of Biology, Medicine and Health, Manchester Academic Health Science Centre, University of Manchester, Manchester, United Kingdom

Background: The care of patients with Rheumatoid Arthritis (RA) is guided by monitoring changes in disease activity. However, whilst a number of patient-related outcome measures (PROMS) exist ${ }^{1}$, they are not collected on an on-going basis. Consequently, there are few objective measurements of disease activity, between clinic visits, to inform treatment decisions. In response to this, the REMORA study (REmote MOnitoring of Rheumatoid Arthritis) is developing a smartphone app, to capture data on disease activity and integrate it directly into the electronic patient record. The project explores whether on-going collection of electronic patient-reported outcomes (ePROS) between clinic visits can enhance clinical care, support patient self-management, and provide a sustainable source of data for research.

Objectives: To describe patients' experiences of remote monitoring of their disease activity, and the perceived value in relation to clinical consultations and self-management.

Methods: A diverse sample of 20 patients with RA entered data into the app over 